\title{
Diurnal gene expression of lipolytic natriuretic peptide receptors in white adipose tissue
}

\author{
Julie Smith², Jan Fahrenkrug ${ }^{3}$, Henrik L Jørgensen ${ }^{3}$, Christina Christoffersen ${ }^{1,4}$ \\ and Jens $\mathbf{P}$ Goetze ${ }^{1,5}$ \\ ${ }^{1}$ Department of Clinical Biochemistry (KB3014), Rigshospitalet, University of Copenhagen, 9 Blegdamsvej, \\ DK-2100 Copenhagen, Denmark \\ ${ }^{2}$ Department of Technology, Faculty of Health and Technology, Metropolitan University College, Copenhagen, \\ Denmark \\ ${ }^{3}$ Department of Clinical Biochemistry, Faculty of Health Sciences, Bispebjerg Hospital, University of Copenhagen, \\ Copenhagen, Denmark \\ ${ }^{4}$ Department of Biomedical Sciences, Copenhagen University, Copenhagen, Denmark \\ ${ }^{5}$ Department of Clinical Medicine, Aarhus University, Aarhus, Denmark
}

\author{
Correspondence \\ should be addressed \\ to J P Goetze \\ Email
}

JPG@dadlnet.dk

\begin{abstract}
Disruption of the circadian rhythm can lead to obesity and cardiovascular disease. In white adipose tissue, activation of the natriuretic peptide receptors (NPRs) stimulates lipolysis. We have previously shown that natriuretic peptides are expressed in a circadian manner in the heart, but the temporal expression profile of their cognate receptors has not been examined in white adipose tissue. We therefore collected peri-renal white adipose tissue and serum from WT mice. Tissue mRNA contents of NPRs - NPR-A and NPR-C, the clock genes Per1 and Bmal1, and transcripts involved in lipid metabolism were quantified at 4-h intervals: in the diurnal study, mice were exposed to a period of $12 \mathrm{~h}$ light followed by $12 \mathrm{~h}$ darkness $(n=52)$. In the circadian study, mice were kept in darkness for $24 \mathrm{~h}(n=47)$. Concomitant serum concentrations of free fatty acids, glycerol, triglycerides (TGs), and insulin were measured. Per1 and Bmal1 mRNA contents showed reciprocal circadian profiles $(P<0.0001)$. NPR-A mRNA contents followed a temporal pattern $(P=0.01)$, peaking in the dark (active) period. In contrast, NPR-C mRNA was expressed in an antiphase manner with nadir in the active period ( $P=0.007)$. TG concentrations in serum peaked in the active dark period $(P=0.003)$. In conclusion, NPR-A and NPR-C gene expression is associated with the expression of clock genes in white adipose tissue. The reciprocal expression may thus contribute to regulate lipolysis and energy homeostasis in a diurnal manner.
\end{abstract}
Key Words
adipocytes
- ANP
- BNP
- receptor
- lipolysis
- circadian
$\checkmark$ diurnal

\section{Introduction}

Mammalian hearts release natriuretic hormones that regulate renal natriuresis and intravascular fluid homeostasis $(1,2)$. More recently, an effect on adipose tissue has also been established in which hormone binding to the cognate receptors induces lipolysis and increased energy expenditure $(3,4,5,6)$. A-type natriuretic peptide (ANP) and B-type natriuretic peptide (BNP) act through a common receptor, natriuretic peptide receptor-A (NPR-A), and a clearance receptor, NPR-C, both expressed in several tissues including heart, kidney, vascular

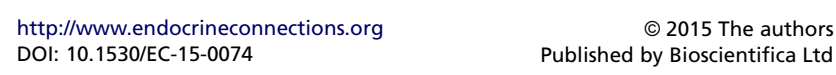


endothelium, and adipocytes. Thus, the endocrine heart is involved not only in hemodynamic regulation but also in energy homeostasis (7).

The sympathetic nervous system plays a key role in overall energy homeostasis. $\beta$-adrenergic receptors on adipocytes are activated by circulating catecholamines that stimulate lipolysis in a cAMP-dependent manner. In parallel, natriuretic peptides cause the release of lipids to the circulation by activating membrane-bound NPR-A receptors on adipocytes via a cGMP-dependent pathway $(2,3,4,5,6)$. Adipocyte lipolysis and energy expenditure activated by ANP and BNP have been reported for both brown and white adipocytes (7). The ratio between the NPR-A and NPR-C receptor activity in adipose tissue has also been suggested to play a role in the fat metabolism, as the NPR-C adjusts the locally available natriuretic peptide concentration by degradation (4).

It is well established that white adipocytes are under regulation by the local clock genes Per1 and Bmal1 $(8,9$, $10,11,12,13)$. In extension, ANP and proANP measurement in human plasma corroborates a diurnal release to circulation, and natriuretic peptide gene expression is temporarily regulated in murine cardiomyocytes $(14,15$, 16 , 17). Taken together, these data suggest that the natriuretic hormone system as a whole could be subject to stringent diurnal regulation, i.e., influenced by light and dark hours. In the present study, we hypothesized that the transcriptional products for NPRs could be associated to local clock genes in white adipose tissue.

\section{Materials and methods}

\section{Animals, blood, and tissue sampling}

Four- to eight-month-old $129 / \mathrm{Sv}$ mice of both genders were used in the study (Table 1). The animals were stabled under standard laboratory conditions with full access to food and water. Experiments were performed in accordance with the law on animal experiments in Denmark (publication \#1306, 23rd November 2007). One group of mice was exposed to a $12 \mathrm{~h}$ light: $12 \mathrm{~h}$ darkness cycle

Table 1 Gender distribution for the ZT and CT groups.

\begin{tabular}{|c|c|c|}
\hline & $\mathbf{Z T}(n=54)$ & CT $(n=48)$ \\
\hline Peri-renal adipose tissue & 23 \%/29 o & 23 \%/24 $0^{\star}$ \\
\hline Lipids in plasma & $24+/ 300$ & 24 \%/24 6 \\
\hline
\end{tabular}

ZT, zeitgeber time; CT, circadian time. $n$, number of mice included from start. (zeitgeber time 0 (ZT0), lights on and ZT12, lights off). Animals were decapitated at the following time points: ZT4, ZT8, ZT12, ZT16, ZT20, and ZT24. Another group of mice was entrained to a $12 \mathrm{~h}$ light: $12 \mathrm{~h}$ darkness cycle for at least 14 days, after which the light was turned off. On the second cycle after transfer into continuous darkness, animals were sacrificed at the same time points as above (circadian time 4 (CT4)-CT24). Blood and tissue samples were obtained at sacrifice. Following decapitation, blood was collected in a tube and allowed to clot at room temperature for $30 \mathrm{~min}$ prior to centrifugation at $1000 \mathrm{~g}$. The serum was stored at $-20^{\circ} \mathrm{C}$ until analysis. Peri-renal white fat tissue $\left(\sim \frac{1}{2} \mathrm{~cm}^{3}\right)$ was excised ventrally to the kidneys. The excised tissue was rapidly frozen on dry ice and stored at $-80^{\circ} \mathrm{C}$.

\section{Tissue mRNA extraction}

Approximately 30-50 mg fat tissue was excised from the frozen biopsies on a metal plate placed on dry ice. The tissue was homogenized at $4{ }^{\circ} \mathrm{C}$ with a TissueLyzer II (Qiagen) in $1 \mathrm{ml}$ TRIzol (Life Technologies) with a metal bead added. The homogenate was immediately stored at $-20{ }^{\circ} \mathrm{C}$ overnight, and, after thawing, the fat phase was carefully removed from the TRIzol homogenate. Otherwise, total RNA was isolated according to the manufacturer's protocol. Concentrations of mRNA were quantified on a NanoDrop 2000 (Thermo Fisher Scientific, Waltham, MA, USA). All samples were kept at $-80^{\circ} \mathrm{C}$. For quality control, mRNA integrity (RIN) was analyzed in a RNA 6000 Nano LabChip using Bioanalyzer 2100 with 2100 Expert Software (Agilent Technologies, Glostrup, Denmark); the RINs were $6.9 \pm 1.3$ (mean \pm s.D.).

\section{Quantification of mRNA}

For transcriptional products, mouse-specific primers were applied for NPR-A and NPR-C quantification. The performance and validation of these mRNA assays has been reported previously (17). Data were normalized with two mouse-specific housekeeping genes: hypoxanthine phosphorybosyl transferase (HPRT) and TATA-binding protein (TBP). From $1 \mu \mathrm{g}$ total RNA, cDNA was synthesized with a high capacity cDNA RT kit (Applied Biosystems) according to the manufacturer's protocol and $2 \mathrm{ng}$ of the synthesized cDNA were used to quantify the specific mRNA in a $10 \mu \mathrm{l}$ reaction including $0.2 \mu \mathrm{l}$ of each primer $(10 \mathrm{pmol} / \mu \mathrm{l})$ and Fast SYBR Green Master Mix P/N4385612 (Applied Biosystems). Samples were quantified in duplicates for muscle and in triplets for fat samples. The relation between the

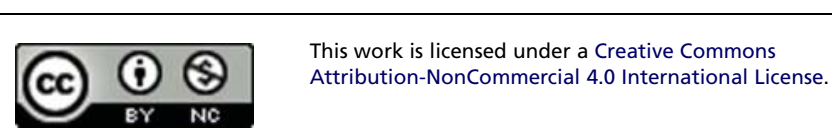


time point of the log-linear increase in fluorescence signal and the relative concentration of an mRNA transcript was determined by analyzing dilutions of a cDNA pool made from $3 \mu$ of each muscle cDNA sample $(n=52)$, i.e., $1: 5$, $1: 10,1: 100,1: 1000$, and 1:10 000. Quantitative real-time PCR analyses were performed with TaqMan ABI PRISM 7900 HT Sequence Detection System (Applied Biosystems) and contents of mRNA were calculated in arbitrary units by the ABI 7000 SDS Software program (Applied Biosystems). Owing to a shoulder on the melting curve after the TaqMan run on the NPR-A primer set, the PCR product was evaluated on a $1 \%$ agarose gel electrophoresis. The two bands were both found to match the genomic sequence corresponding to NPR-A after purification by Illustra GFX PCR and Gel Band Purification Kit and after sequencing (GE Healthcare, Brøndby, Denmark). Quantitative realtime PCR analyses were performed with TaqMan ABI PRISM 7900 HT Sequence Detection System (Applied Biosystems). Data for each gene were normalized with two housekeeping genes: HPRT and TBP or glyceraldehyde-3-phosphate dehydrogenase (GAPDH).

Sense and antisense primers for GAPDH, NPR-A, NPR-C, and genes coding for transcripts involved in lipid handling - peroxisomal proliferator-activated receptor alpha (PPAR $\alpha)$, PPAR $\gamma$, lipoprotein lipase (LPL), cluster of

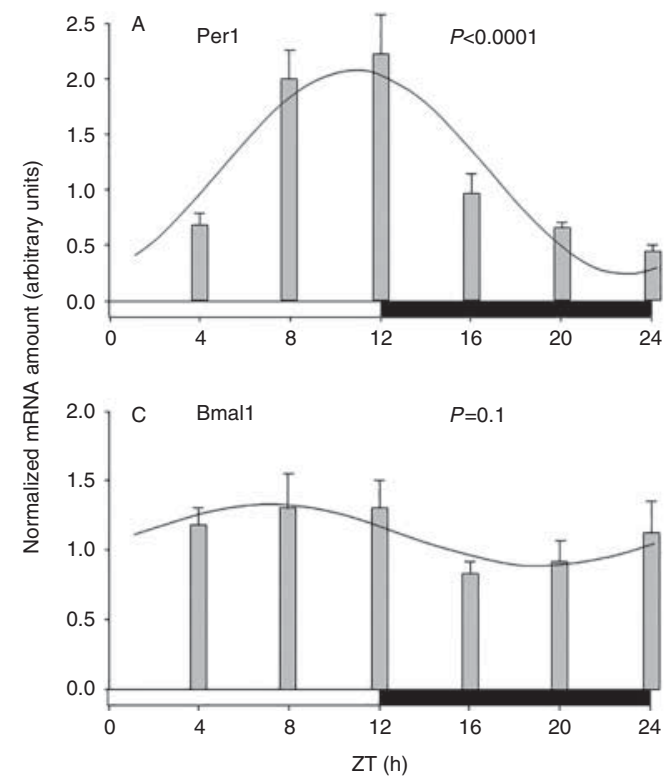

\section{Figure 1}

Rhythmic changes in the expression of the clock genes Per1 (A) and Bmal1 (C) and the natriuretic peptide receptors NPR-A (B) and NPR-C (D) in white adipose tissue during a $12 \mathrm{~h}$ light: $12 \mathrm{~h}$ darkness cycle. Mice were killed at 4- $h$ intervals and mRNA levels were measured using quantitative real-time RT-PCR and normalized with two housekeeping genes (see 'Materials and differentiation 36 (CD36), fatty acid-binding protein 1 (FATP1), FATP4, carnitine palmitoyltransferase 1 (CPT1), long chain acyl-CoA-dehydrogenase (LCAD), glucose transporter 4 (GLUT4), and diacylglycerol acetyltransferase (DGAT) - are described previously $(18,19)$. The following mouse specific primer sequences genes were used: NPR-A: $5^{\prime}$-agt acg cca aca acc tgg ag, 3'-aag agc tgt aaa gcc cac ga; NPR-C: $5^{\prime}$-tga cac cat tcg gag aat ca, $3^{\prime}$-ttt cac ggt cet cag tag gg; HPRT: $5^{\prime}$-aag ctt gct ggt gaa aag ga, $3^{\prime}-$ ttg cgc tca tct tag gct tt; TBP: $5^{\prime}$-taa tcc caa gcg att tgc tgc, $3^{\prime}$-ctt cac atc aca gct ccc ca; hormone-sensitive lipase (HSL): $5^{\prime}$-tgc tct tct tcg agg gtg at, $3^{\prime}$-tct cgt tgc gtt tgt agt gc; and FABP4: $5^{\prime}$-acg aca gga agg tga aga gc, $3^{\prime}$-aaa ttt cca tcc agg cct ct.

For quantification of the clock genes, Bmal1 and Per1, TaqMan gene expression were applied (Mm0050 1813_m1 and Mm0050226_m1 respectively; Applied Biosystems). For standardization of data, mouse specific hypoxanthine-guanine phosphoribosyltransferase (HPRT, Mm_00437762_m1 and Mm00446968_m1) was chosen as a housekeeping gene and assayed as previously described (20). Samples were analyzed in duplicates by mixing samples with TaqMan Gene Expression Master Mix (Applied Biosystems) to a final volume of $10 \mu \mathrm{l}$ and quantified by fluorescence, also using the TaqMan ABI PRISM HT7900 System.
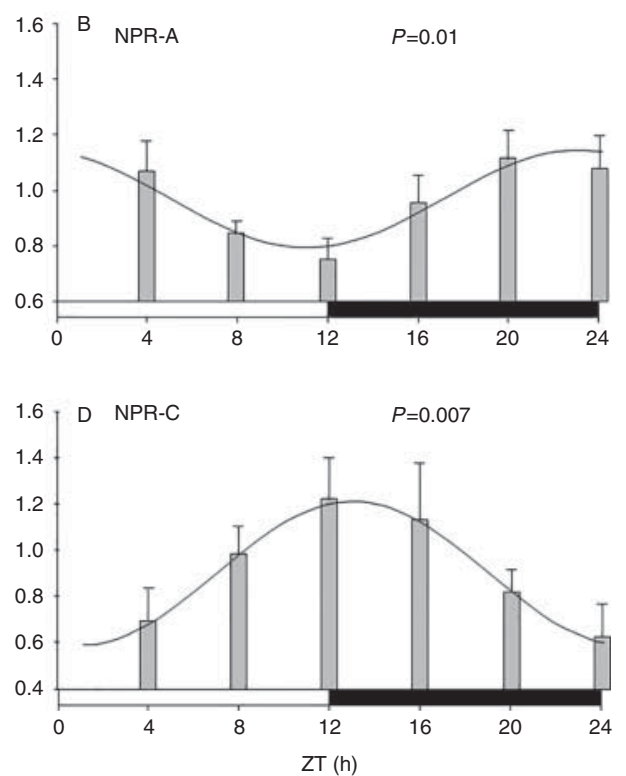

methods' section). Values are given as means \pm S.E.M., $n=8$ or 9 samples at each time point. Fitted curves to the rhythmic changes have been drawn. The white bars at the bottom of the graphs represent the period of light (ZT0-ZT12) and the black bars represent the period of darkness (ZT12-ZT24). ZT, zeitgeber time.

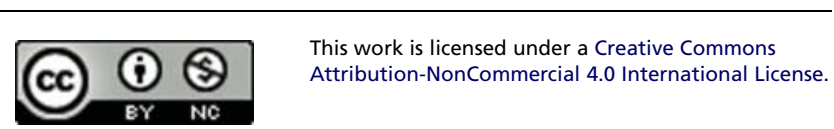


Measurement of triglycerides, free fatty acids, glycerol, and insulin in serum

Enzymatic kits were used to determine serum concentrations of triglycerides (TGs) and glycerol (GPO-TRINDER; Sigma) and free fatty acids (FFA) (WAKO NEFA C Kit; TriChem Aps, Frederikssund, Denmark). Five microlitre of serum were analyzed in duplicate; for internal control we used calibrators from Roche and TriChem Aps. For measurement of insulin, we used an ELISA from DRG International (Springfield, NJ, USA).

\section{Statistical analyses}

To analyze for temporal changes in the mRNA contents of natriuretic receptors, clock genes, and plasma lipids, $X_{\mathrm{cos}}$ and $X_{\sin }$ were calculated for each time point $(t): X_{\cos }=$ $\operatorname{COS}(2 \pi t / 24)$ and $X_{\sin }=\operatorname{SIN}(2 \pi t / 24)$. Based on cosinorrhythmometry as described by Nelson et al. (21), $X_{\mathrm{cos}}$ and $X_{\text {sin }}$ were fitted into a combined cosine and sine function together with mRNA contents measured at the corresponding time: $\mathrm{mRNA}=M+k_{1} X_{\cos }+k_{2} X_{\sin }$. Subsequently, the model fit was tested using the general linear model procedure in the SAS Statistical Software package. $P$ values $<0.05$ were considered significant. Groups are presented on the figures by mean \pm s.E.M. Simple linear regression and correlation coefficient $R^{2}$ were applied to test correlations between receptor NPR-A and plasma variables.

\section{Results}

\section{Animals}

Table 1 shows the distribution of animal gender in the ZT and CT groups, and the number of included samples. Four samples were excluded due to manual errors in the RNA extraction phase.

\section{Light/darkness cycle (diurnal variations)}

To test for diurnal variations, the mRNA contents of the known clock genes Per1 and Bmal1 were measured in perirenal white adipose tissue from the murine ZT groups. The results indicate that the adipose tissue is regulated by a local clock, where Per1 mRNA contents oscillated with a peak value at ZT12 for the light/darkness exposed mice $(P<0.0001$; Fig. 1A). However, clock gene Bmal1 only showed a diurnal trend with nadir at ZT16, but no rhythmic pattern was statistically evident from these data (Fig. 1C). The expression of the NPR-A gene oscillated
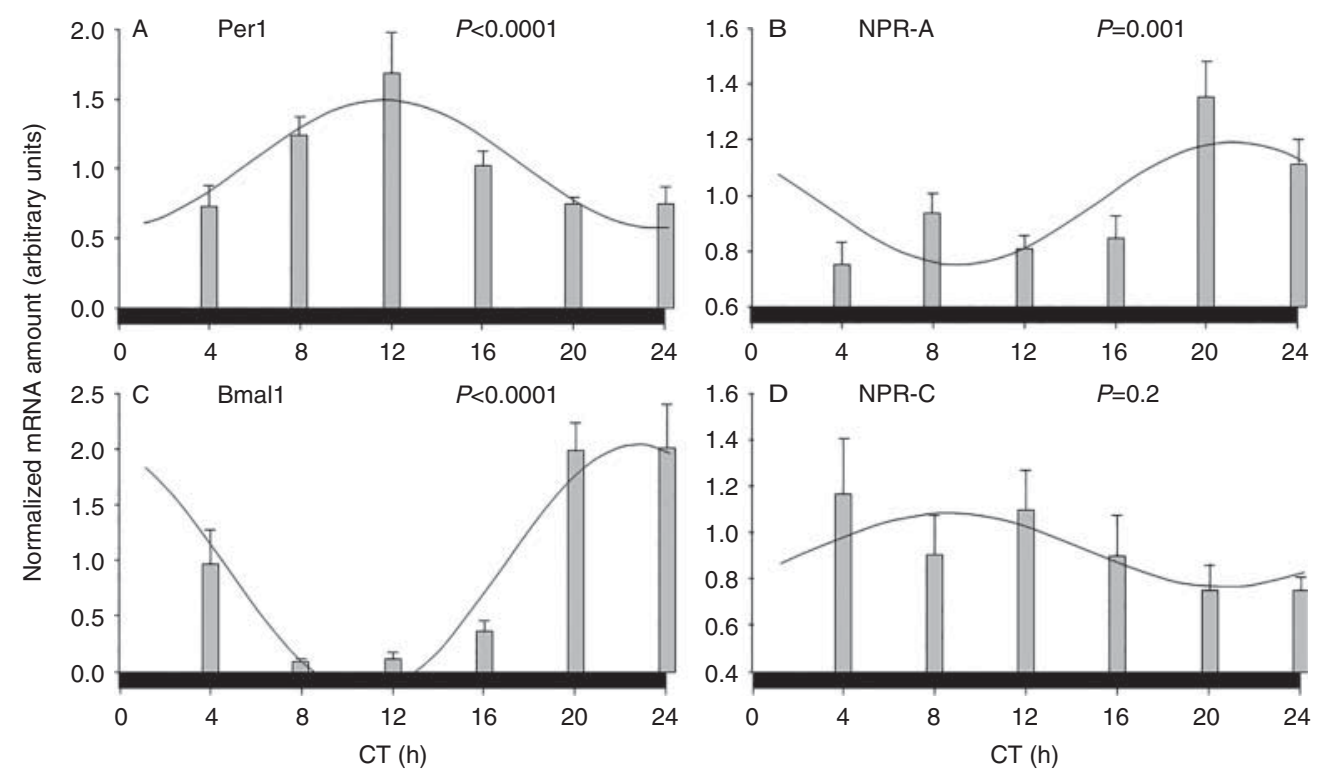

\section{Figure 2}

Rhythmic changes in the expression of the clock genes Per1 (A) and Bmal1 (C) and the natriuretic peptide receptors NPR-A (B) and NPR-C (D) in white adipose tissue during continuous darkness. Mice were killed at $4-h$ intervals and mRNA levels were measured using quantitative real-time RT-PCR and normalized with two housekeeping genes (see 'Materials and methods' section). Values are given as means \pm s.E.M., $n=8$ at each time point ( $n=7$ for ZT16). Fitted curves to the rhythmic changes have been drawn. The black bars at the bottom of the graphs represent the period of darkness. $\mathrm{CT}$, circadian time. 
Table 2 Transcripts involved in lipid metabolism and cosinor-rhythmometry statistics with results listed as $P$ values for oscillation.

\begin{tabular}{|c|c|c|c|c|c|c|c|c|c|c|c|c|}
\hline & LPL & FATCD36 & FATP1 & FATP4 & GLUT4 & $\operatorname{PPAR} \alpha$ & $\operatorname{PPAR} \gamma$ & CPT1 & FABP4 & LCAD & DGAT & HSL \\
\hline ZT & 0.750 & 0.310 & 0.230 & 0.470 & 0.550 & 0.000 & 0.760 & 0.009 & 0.604 & 0.333 & 0.584 & 0.541 \\
\hline $\mathrm{CT}$ & 0.328 & 0.294 & 0.610 & 0.229 & 0.464 & 0.020 & 0.539 & 0.452 & 0.368 & 0.135 & 0.805 & 0.508 \\
\hline
\end{tabular}

ZT, zeitgeber time; CT, circadian time.

significantly with nadir at ZT12 when mice were exposed to a light/darkness cycle $(P=0.01$; Fig. $1 \mathrm{~B})$, and expression of the clearance receptor NPR-C peaked in the light/ darkness cycle at ZT12 ( $P=0.007$; Fig. 1D), thus oscillating in antiphase compared to the NPR-A lipolytic receptor.

\section{Dark/darkness cycle (circadian variations)}

The genes of interest were also tested on mice kept in complete darkness. For the circadian regulated clock gene Per1, mRNA contents peaked at CT12 $(P<0.0001$; Fig. 2A), and as expected, the temporal pattern for Bmal1 was regulated in an antiphase manner to Per1 with nadir at
CT12 $(P<0.0001 ;$ Fig. 2C). The mRNA contents of the receptors involved in lipolysis, NPR-A and NPR-C, are shown in Fig. 2. The lipolytic receptor NPR-A seems to be circadian regulated ( $P=0.001$; Fig. $2 \mathrm{~B}$ ), where the expression profile is similar to the ZT mice kept in the light/darkness cycle. The clearance receptor, NPR-C, did not show a significant rhythmic expression in constant darkness (Fig. 2D).

\section{Transcripts involved in lipid metabolism}

Transcripts for genes involved in lipid metabolism revealed significant oscillation in both $\mathrm{ZT}$ and CT animals for PPAR $\alpha$ and for CPT1 in ZT (Table 2 and Fig. 3).
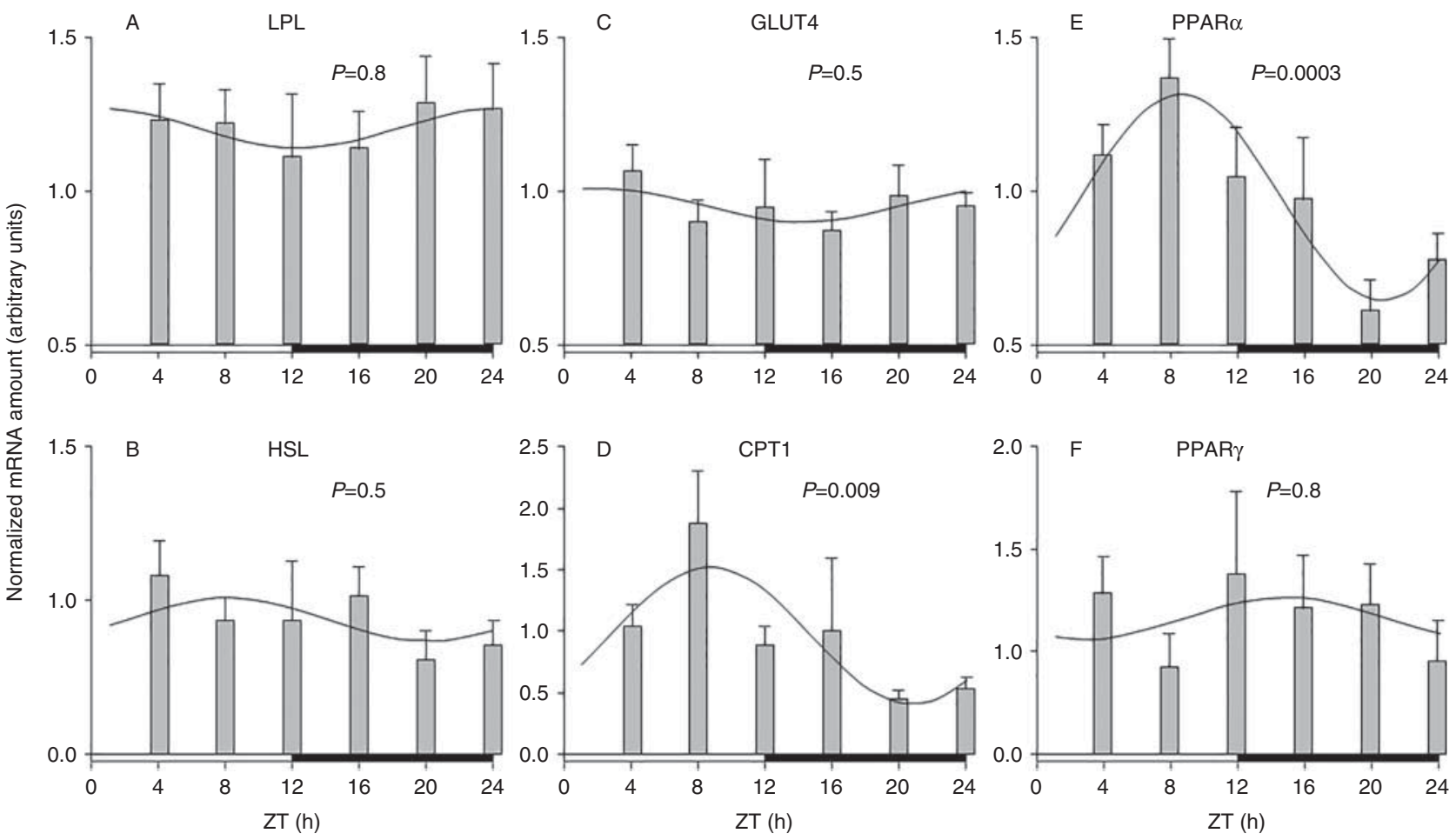

Figure 3

(A-F) Oscillation profiles of selected transcripts involved in lipid metabolism (only ZT time). Values are given as means \pm s.E.M., $n=8$ or 9 samples at each time point. Fitted curves to the rhythmic changes have been drawn. The white bars at the bottom of the graphs represent the period of light

\begin{tabular}{lr}
\hline http://www.endocrineconnections.org & $\odot 2015$ The authors \\
DOI: $10.1530 /$ EC-15-0074 & Published by Bioscientifica Ltd
\end{tabular}

(ZT0-ZT12) and the black bars represent the period of darkness (ZT12-ZT24). LPL, lipoprotein lipase; HSL, hormone-sensitive lipase; GLUT4, glucose transporter 4; CPT1, carnitine palmitoyltransferase 1; PPAR $\alpha$, peroxisomal proliferator-activated receptor alpha; ZT, zeitgeber time.

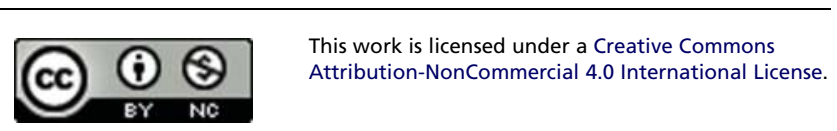



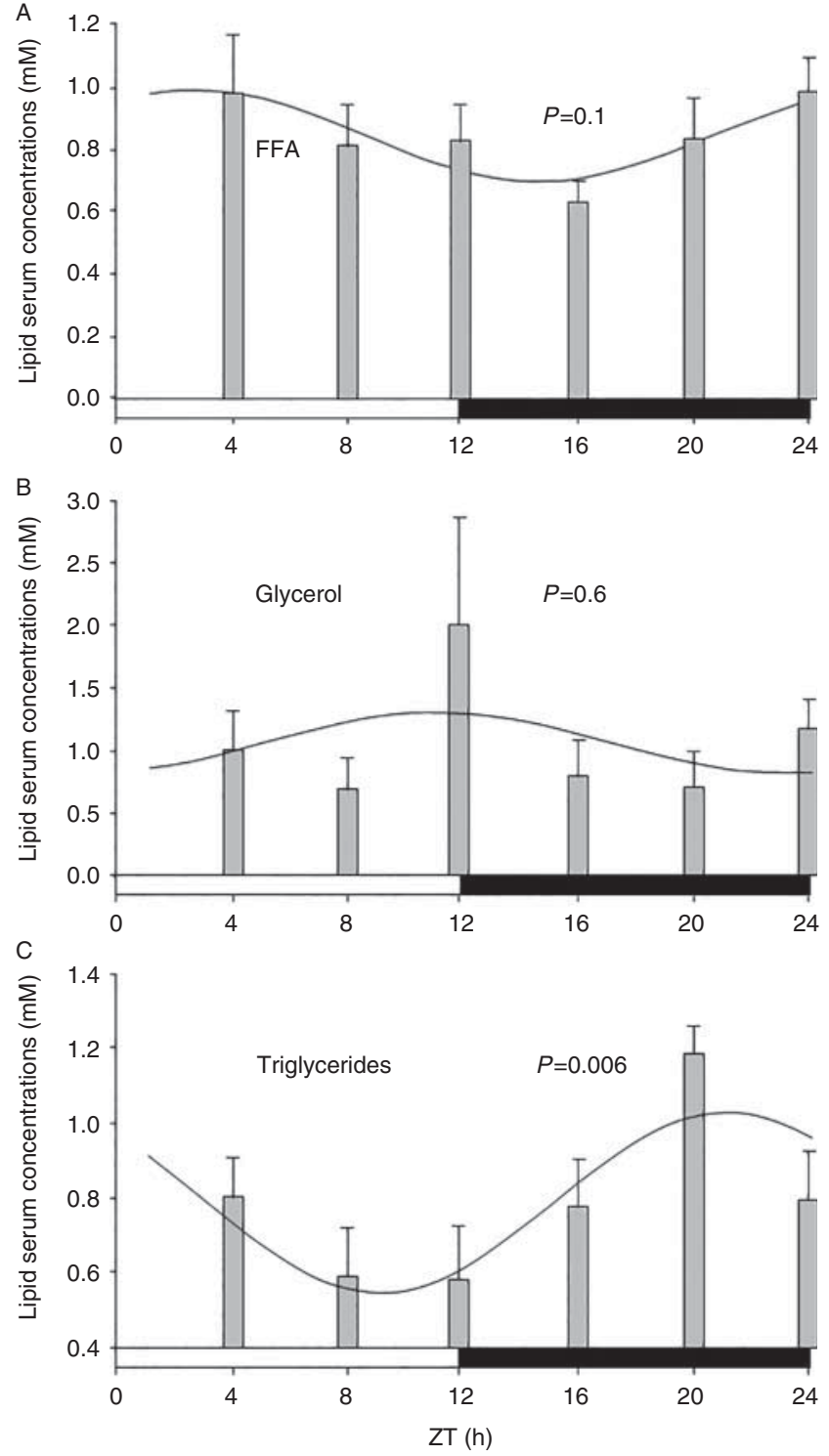

Figure 4

Concentrations of free fatty acids (FFA) (A), glycerol (B), and triglycerides (C) in mouse serum during a $12 \mathrm{~h}$ light: $12 \mathrm{~h}$ darkness cycle. Blood was sampled at 4-h intervals. Values are given as means \pm s.E.M., $n=9$ at each time point. Fitted curves to the rhythmic changes have been drawn.

The white bars at the bottom of the graphs represent the period of light (ZTO-ZT12) and the black bars represent the period of darkness (ZT12-ZT24). ZT, zeitgeber time.

In contrast, no changes over time were observed for HSL or LPL.

\section{Lipids and insulin in serum}

For the ZT group, e.g., mice kept in the light/darkness cycle, only TG in plasma oscillated significantly as shown in Fig. 4C. In the CT group (dark/darkness cycle), TG and glycerol oscillated significantly as shown in Fig. 5B and C. These plasma variables suggest a similar pattern of oscillation as for the mRNA expression of NPR-A with nadir at ZT12 or CT12; the correlations between the phenotype and genotype variables are presented in Table 3. Insulin measurement did not display a significant oscillation pattern (data not shown).

\section{Discussion}

Cardiac natriuretic peptides are involved in energy homeostasis, and the cognate receptors NPR-A and NPR-C are expressed on adipocytes $(2,3,4,5,6,7)$. White adipocytes are regulated by a local clock function with the rhythmic changes of Per1 and Bmal1, which is also confirmed in the present study $(8,9,13)$. Moreover, our data reveal that NPR-A and NPR-C are regulated in a temporal antiphase manner, and we also observed similar variations in circulating lipids, the phenotype for ongoing lipolysis.

The suprachiasmatic nucleus in the hypothalamus and peripheral clocks in other cells of the organism provide a 'time-keeping system' that controls most endocrine organs. This biological clock has recently been suggested to be one of the regulating factors in adipose metabolism $(10,11,22)$. Circulating lipids are affected by dietary intake (23), but they are also released in a circadian manner, which is most noticeable during fasting periods $(10,11,12)$. Our mice were allowed to feed ad libitum despite the known postprandial effect; however, the temporal rhythmic variations in plasma and adipose tissue were still noticeable.

It has previously been suggested that the natriuretic peptides do not have a lipolytic effect in mice adipocytes but may be more a primate-specific mechanism (24). Recently, however, Bordicchia et al. (4) showed that the ratio of NPR-A/NPR-C gene expression in mice regulates the metabolic effects, and lipolysis is evident in NPR-C deficient mice.

Cardiac hormones (ANP and BNP) in circulation stimulate the adipocyte membrane-bound NPR-A receptor and lipolysis is activated. The overall effect is increased lipolysis if this occurs concomitantly with a downregulation of the NPR-C clearance receptor on the adipocytes $(2,3,4,5,6,7)$. In our study, murine adipose NPR-A and NPR-C genes are expressed in an antiphase manner during day and night, which supports the relevance of the NPR-A/NPR-C ratio and diurnal regulations. During active hours (for mice in the

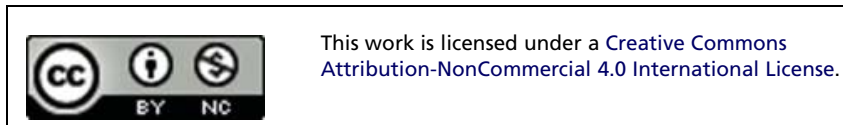




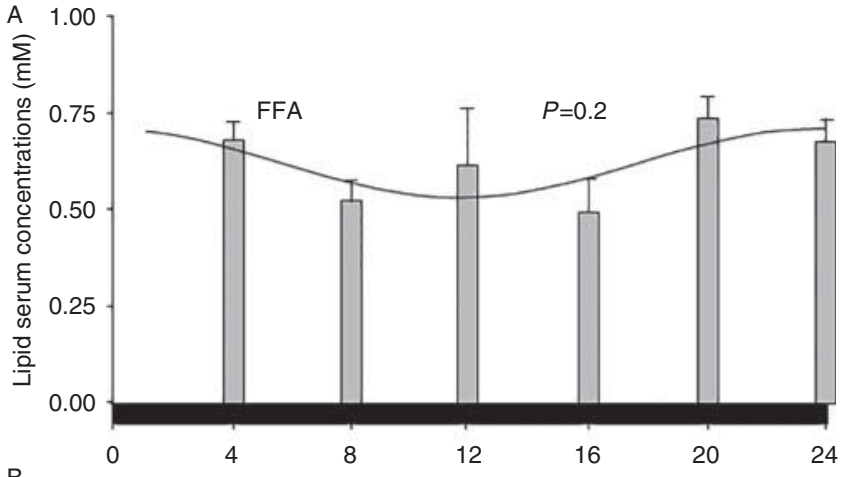

B
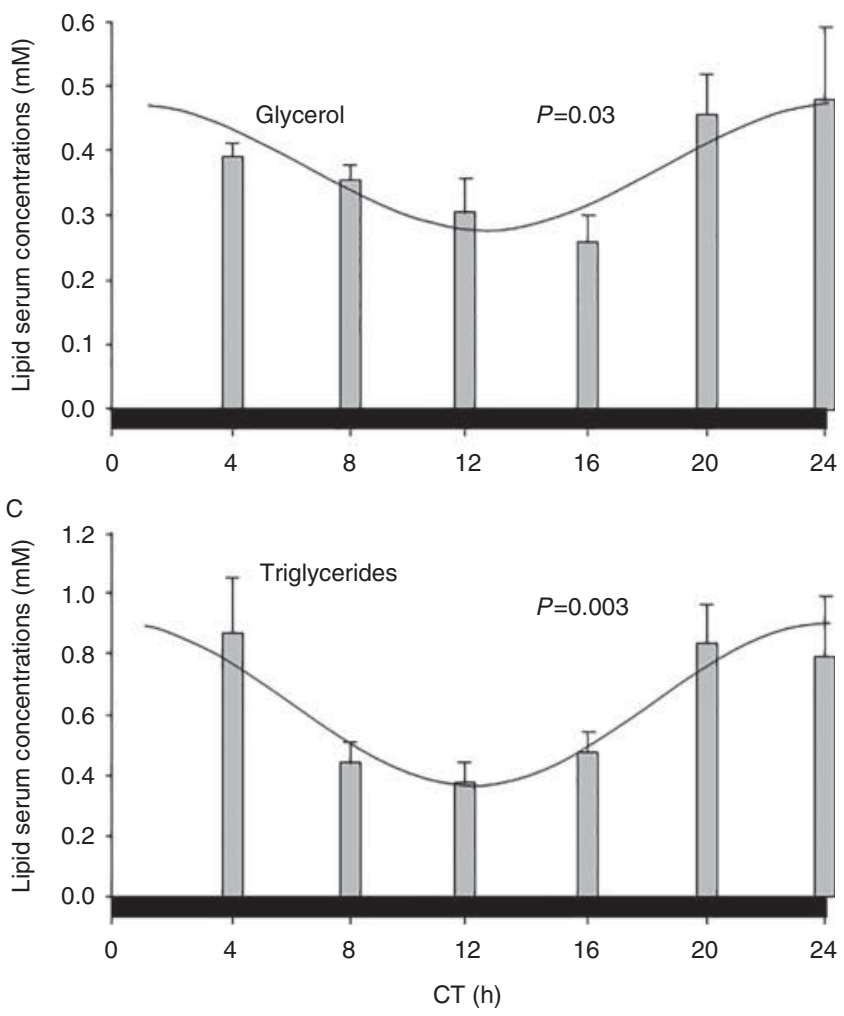

Figure 5

Concentrations of free fatty acids (FFA) (A), glycerol (B), and triglycerides (C) in mouse serum during continuous darkness. Blood was sampled at 4-h intervals. Values are given as means \pm s.E.M., $n=8$ at each time point. Fitted curves to the rhythmic circadian changes have been drawn. The black bars at the bottom of the graphs represent the period of darkness. CT, circadian time.

dark hours), NPR-A gene expression increases and NPR-C expression decreases, which may result in diurnal lipolysis as also suggested by the serum measurements. However, the NPR-A/NPR-C ratio did not correlate with the circadian plasma profiles, but circulating lipids are also regulated by other biological mechanisms including catecholamines.
We and others have shown that natriuretic peptides in plasma and the cardiac gene expression are regulated in a circadian manner $(13,14,15,16)$. However, the NPR-A and NPR-C expression within the heart muscle does not seem to be regulated by an internal clock (14), which is in contrast to our data in adipose tissue. This suggests that all physiological effects of the hormones are not necessarily under a uniform day/night regulation but may be a characteristic for energy/fat homeostasis, as also suggested from the correlation analyses between receptor mRNA expression and FFA in serum (Table 2). In extension, local differences in white adipose tissue are well known, for instance, most white fat is subcutaneous (25). However, lipolytic effects of natriuretic peptides have been reported as equal for subcutaneous and visceral fat (26), which makes it tempting to speculate that our findings in peri-renal white fat tissue may also apply to the subcutaneous adipose tissue.

Transcripts involved in lipid metabolism only revealed significant oscillation for PPAR $\alpha$ in both the ZT and CT animals (Table 3). This in vivo finding contrasts earlier results from adipocytes in vitro (27). Interestingly, PPAR $\alpha$ is a transcription factor involved not only in lipid metabolism but also in the internal regulation of the clock gene Bmal1 (28). To our knowledge, there is no data on the possible regulation of NPR expression by PPAR $\alpha$, but the diurnal and circadian profiles of both mRNA contents make it tempting to speculate that activation of $\operatorname{PPAR} \alpha$ could affect the receptor expression. Notably, this is pharmacologically feasible via compounds like eicosanoids, arachidonic acid, or hypolipidemic fibrates that activate the PPAR $\alpha$ transcription factor (28).

Table 3 Linear regression with correlations between mRNA contents and lipids in serum: dependent variable NPR-A mRNA content in murine peri-renal white adipose tissue compared to corresponding measurements of serum lipids as independent variables.

\begin{tabular}{|c|c|c|c|c|}
\hline Time & Gene & Triglycerides & $\begin{array}{l}\text { Free fatty } \\
\text { acids }\end{array}$ & Glycerol \\
\hline \multirow[t]{2}{*}{ ZT } & NPR-A & NS & $\begin{array}{r}P=0.01 \\
r=0.36\end{array}$ & NS \\
\hline & NPR-A/NPR-C & NS & $\begin{array}{r}P=0.005 \\
r=0.39\end{array}$ & NS \\
\hline \multirow[t]{2}{*}{ CT } & NPR-A & NS & NS & $\begin{array}{r}P=0.03 \\
r=0.30\end{array}$ \\
\hline & NPR-A/NPR-C & NS & NS & $\begin{array}{r}P=0.01 \\
r=0.37\end{array}$ \\
\hline
\end{tabular}

$\mathrm{ZT}$, zeitgeber time; CT, circadian time; NS, non-significant; NPR, natriuretic peptide receptor.

This work is licensed under a Creative Commons Attribution-NonCommercial 4.0 International License. 


\section{Limitations}

Our study represents data based on mRNA measurements supporting the hypothesis that natriuretic receptors involved in lipolysis are regulated by an internal clock in white adipose tissue. Clearly, measurement of the functional products, e.g., receptor binding and intracellular activation, would represent the actual phenotype. However, antibody staining targeted at the receptors is not a quantitative method, and we are not aware of a quantitative method for measuring the receptor protein. Moreover, a tissue-specific knockout model of the local clock in adipose tissue would be highly informative in terms of mechanism. We suggest that this should be pursued in future experiments.

\section{Declaration of interest}

The authors declare that there is no conflict of interest that could be perceived as prejudicing the impartiality of the research reported.

\section{Funding}

The study was supported by the Danish Biotechnology Center for Cellular Communication and the Novo Nordisk Foundation.

\section{Acknowledgements}

The skillful laboratory assistance from Lis Schütt Nielsen is gratefully acknowledged.

\section{References}

1 Goetze JP. B-type natriuretic peptide: from posttranslational processing to clinical measurement. Clinical Chemistry 201258 83-91. (doi:10. 1373/clinchem.2011.165696)

2 Zois NE, Bartels ED, Hunter I, Kousholt BS, Olsen LH \& Goetze JP. Natriuretic peptides in cardiometabolic regulation and disease. Nature Reviews. Cardiology 201411 403-412. (doi:10.1038/nrcardio.2014.64)

3 Sengenès C, Berlan M, De Glisezinski I, Lafontan M \& Galitzky J. Natriuretic peptides: a new lipolytic pathway in human adipocytes. FASEB Journal 200014 1345-1351.

4 Bordicchia M, Liu D, Amri EZ, Ailhaud G, Dessì-Fulgheri P, Zhang C, Takahashi N, Sarzani R \& Collins S. Cardiac natriuretic peptides act via p38 MAPK to induce the brown fat thermogenic program in mouse and human adipocytes. Journal of Clinical Investigation 2012122 1022-1036. (doi:10.1172/JCI59701)

5 Sengenes C, Bouloumie A, Hauner H, Berlan M, Busse R, Lafontan M \& Galitzky J. Involvement of a cGMP-dependent pathway in the natriuretic peptide-mediated hormone-sensitive lipase phosphorylation in human adipocytes. Journal of Biological Chemistry 2003278 48617-48626. (doi:10.1074/jbc.M303713200)

6 Potter LR \& Hunter T. Guanylyl cyclase-linked natriuretic peptide receptors: structure and regulation. Journal of Biological Chemistry 2001 276 6057-6060. (doi:10.1074/jbc.R000033200)

7 Collins S. A heart-adipose tissue connection in the regulation of energy metabolism. Nature Reviews. Endocrinology 201410 157-163. (doi:10.1038/nrendo.2013.234)
8 Bray MS \& Young ME. Circadian rhythms in the development of obesity: potential role for the circadian clock within the adipocyte. Obesity Reviews 20078 169-181. (doi:10.1111/j.1467-789X.2006. 00277.x)

9 Gómez-Santos C, Gómez-Abellán P, Madrid JA, Hernández-Morante JJ, Lujan JA, Ordovas JM \& Garaulet M. Circadian rhythm of clock genes in human adipose explants. Obesity 200917 1481-1485.

10 Shostak A, Meyer-Kovac J \& Oster H. Circadian regulation of lipid mobilization in white adipose tissues. Diabetes 201362 2195-2203. (doi:10.2337/db12-1449)

11 Chua EC, Shui G, Lee IT, Lau P, Tan LC, Yeo SC, Lam BD, Bulchand S, Summers SA, Puvanendran K et al. Extensive diversity in circadian regulation of plasma lipids and evidence for different circadian metabolic phenotypes in humans. PNAS 2013110 14468-14473. (doi:10.1073/pnas.1222647110)

12 Morgan L, Arendt J, Owens D, Folkard S, Hampton S, Deacon S English J, Ribeiro D \& Taylor K. Effects of the endogenous clock and sleep time on melatonin, insulin, glucose and lipid metabolism. Journal of Endocrinology 1998157 443-451. (doi:10.1677/joe.0. 1570443)

13 Otway DT, Mäntele S, Bretschneider S, Wright J, Trayhurn P, Skene DJ Robertson MD \& Johnston JD. Rhythmic diurnal gene expression in human adipose tissue from individuals who are lean, overweight, and type 2 diabetic. Diabetes 201160 1577-1581. (doi:10.2337/ db10-1098)

14 Martino TA, Tata N, Belsham DD, Chalmers J, Straume M, Lee P, Pribiag H, Khaper N, Liu PP, Dawood F et al. Disturbed diurnal rhythm alters gene expression and exacerbates cardiovascular disease with rescue by resynchronization. Hypertension 200749 1104-1113. (doi:10.1161/HYPERTENSIONAHA. 106.083568)

15 Goetze JP, Georg B, Jørgensen HL \& Fahrenkrug J. Chamber-dependent circadian expression of cardiac natriuretic peptides. Regulatory Peptides 2010160 140-145. (doi:10.1016/j.regpep.2009.12.010)

16 Goetze JP, Jørgensen HL, Sennels HP \& Fahrenkrug J. Diurnal plasma concentrations of natriuretic propeptides in healthy young males. Clinical Chemistry 201258 789-792. (doi:10.1373/clinchem.2011. 178921)

17 Sothern RB, Vesely DL, Kanabrocki EL, Hermida RC, Bremner FW, Third JL, Boles MA, Nemchausky BM, Olwin JH \& Scheving LE. Temporal (circadian) and functional relationship between atrial natriuretic peptides and blood pressure. Chronobiology International 199512 106-120. (doi:10.3109/07420529509064506)

18 Christoffersen C, Bollano E, Lindegaard ML, Bartels ED, Goetze JP, Andersen CB \& Nielsen LB. Cardiac lipid accumulation associated with diastolic dysfunction in obese mice. Endocrinology 2003144 3483-3490. (doi:10.1210/en.2003-0242)

19 Christoffersen C, Bartels ED \& Nielsen LB. Heart specific up-regulation of genes for B-type and C-type natriuretic peptide receptors in diabetic mice. European Journal of Clinical Investigation 200636 69-75. (doi:10.1111/j.1365-2362.2006.01596.x)

20 Georg B, Hannibal J \& Fahrenkrug J. Lack of the PAC1 receptor alters the circadian expression of VIP mRNA in the suprachiasmatic nucleus of mice. Brain Research 20071135 52-57. (doi:10.1016/j.brainres.2006. 12.001)

21 Nelson W, Tong YL, Lee JK \& Halberg F. Methods for cosinorrhythmometry. Chronobiologia 19796 305-323.

22 Shostak A, Husse J \& Oster H. Circadian regulation of adipose function Adipocyte 20132 201-206. (doi:10.4161/adip.26007)

23 Carey PE, Halliday J, Snaar JE, Morris PG \& Taylor R. Direct assessment of muscle glycogen storage after mixed meals in normal and type 2 diabetic subjects. American Journal of Physiology. Endocrinology and Metabolism 2003284 E688-E694. (doi:10.1152/ ajpendo.00471.2002)

24 Sengenès C, Zakaroff-Girard A, Moulin A, Berlan M, Bouloumié A, Lafontan M \& Galitzky J. Natriuretic peptide-dependent lipolysis

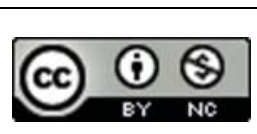

This work is licensed under a Creative Commons Attribution-NonCommercial 4.0 International License. 
in fat cells is a primate specificity. American Journal of Physiology. Regulatory, Integrative and Comparative Physiology 2002 283 R257-R265.

25 Frühbeck G, Méndez-Giménez L, Fernández-Formoso JA, Fernández S \& Rodríguez A. Regulation of adipocyte lipolysis. Nutrition Research Reviews 201427 63-93.

26 Dicker A, Åström G, Wåhlén K, Hoffstedt J, Näslund E, Wirén M, Rydén M, Arner P \& van Harmelen V. Primary differences in lipolysis between human omental and subcutaneous adipose tissue observed using in vitro differentiated adipocytes. Hormone and Metabolic Research 200941 350-355. (doi:10.1055/s-0028-1112135)

27 Otway DT, Frost G \& Johnston JD. Circadian rhythmicity in murine pre-adipocyte and adipocyte cells. Chronobiology International 200926 1340-1354. (doi:10.3109/07420520903412368)

28 Lecarpentier Y, Claes V, Duthoit G \& Hébert JL. Circadian rhythms, Wnt $/ \beta$-catenin pathway and PPAR $\alpha / \gamma$ profiles in diseases with primary or secondary cardiac dysfunction. Frontiers in Physiology 20145429. (doi:10.3389/fphys.2014.00429)

Received in final form 3 August 2015

Accepted 18 August 2015
This work is licensed under a Creative Commons Attribution-NonCommercial 4.0 International License. 